\title{
The Relationship between Abnormal Echocardiography Findings in Fetus with Small Gestational Age
}

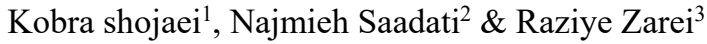 \\ ${ }^{1}$ Obstetric \& Gynecologist, Fellowship of Perinatalogy, Faculty of Medicine, Fertiliry Infertility and \\ Perinatalogy Center, Ahvaz Jundishapur University of Medical Seiences, Ahvaz, Iran \\ ${ }^{2}$ Fertility, Infertility and Perinatology Research Center, Ahvaz Jundishapur University of Medical Sciences, \\ Ahvaz, Iran \\ ${ }^{3}$ Faculty of Medicine, Fertility, Infertility and Perinatology Center, Ahvaz Jundishapur University of Medical \\ Sciences, Ahvaz, Iran \\ Correspondence: Raziye Zarei, Faculty of Medicine, Fertility, Infertility and Perinatology Center, Ahvaz \\ Jundishapur University of Medical Sciences, Ahvaz, Iran. Tel: +98-61-2439-152.
}

Received: May 7, 2020

doi:10.5539/jmbr.v10n1p112
Accepted: July 7, 2020

Online Published: November 30, 2020

URL: https://doi.org/10.5539/jmbr.v10n1p112

\begin{abstract}
Background: Intrauterine growth restriction (IUGR), refers to a condition in which the fetus does not grow well according to its genetic potential. Development of the cardiovascular system and impairing fetal developmental planning ultimately caused long-term cardiovascular morbidity. In the present study, the incidence of cardiac abnormalities in fetuses affected by IUGR as well as factors related to the occurrence of these abnormalities were evaluated.
\end{abstract}

Material and Methods: In this descriptive-analytical study, pregnant women referred to the Imam Khomeini Hospital in Ahvaz during February 2018 to January 2020 were recruited. Complete clinical information was recorded using a questionnaire. The recorded information included age, birth weight, gestational age, weight and BMI and comorbidities. Then, echocardiographic data; structural abnormalities including septal condition, valves and outflow of large arteries, and the presence of mass or oxygen in the heart and pulmonary arteries, EF and HR, were extracted from the medical records.

Results: In the present study, 152 patients were studied. The mean age of patients was 28.2 ranged from 17 - to 40year. Fetal echocardiography showed that nearly $60 \%$ of fetuses had heart abnormalities. The most common disease was ventricular septal defect (VSD) $(\mathrm{n}=21,13.8 \%)$, followed by atrial septal defec(ASD) $(\mathrm{n}=$ $15,9.9 \%)$ and concurrent ASD and VSD was observed in of $11.2 \%$ cases $(n=17)$. The incidence of echocardiographic abnormalities in IUGR fetuses was significantly higher than in SGA $(p=0.0001)$. However, the type of IUGR did not have a significant relationship with the incidence of echocardiographic findings in terms of time of performance (Early or late). Among the Doppler ultrasound factors, uterine artery PI $(\mathrm{p}=0.001)$ and umbilical artery PI $(p=0.008)$ were associated with fetal heart abnormalities.

Conclusion: In general, the findings of this study showed that the incidence of heart disorders in IUGR fetuses is high and is related to the severity of fetal growth restriction. Cardiac abnormalities are more common in IUGR fetuses than in SGA. Our results have also shown that the umbilical artery PI and uterine artery PI can be used as predictive factors in diagnosing fetal heart abnormalities. Our findings suggest an evaluation of echocardiography in IUGR fetuses.

\section{Introduction}

Intrauterine growth restriction (IUGR), refers to a condition in which the fetus does not grow well according to its genetic potential (Sharma, Shastri, \& Sharma, 2016). One of the main causes of IUGR is vascular insufficiency of the placenta (Krishna \& Bhalerao, 2011). Under these conditions, the deprivation of oxygen and nutrients causes the IUGR fetus to make certain changes in its blood circulation. These changes are due to adaptability to the intrauterine suboptimal environment. These adaptations are aimed at providing oxygen and nutrients to vital organs such as heart, brain, and adrenal glands. These adaptations in blood circulation may alter the development of the cardiovascular system and impair fetal developmental planning and ultimately caused 
long-term cardiovascular morbidity (Cohen, Wong, Horne, \& Yiallourou, 2016).

Congenital heart defects are currently the most common congenital anomalies at birth, with an incidence of 8 to 10 per 1,000 live births (Drose, 2013). According to the World Health Organization, between 1950 and 1996, $72 \%$ of infant deaths were due to heart problems (Carvalho, Allan, Chaoui, Copel, ..., \& Yagel, 2013). One of the most difficult prenatal diagnoses is screening for fetal heart defects (Satomi, 2015). Using screening tests and with prescribing prophylactic folic acid have gradually eliminated major neural tube defects and common trisomy, and lead to rise the cardiac anomalies from third to first congenital anomalies. Of course, the presence of known and unknown teratogens and the increase in age of first pregnancy should also be considered. On the other hand, despite the invention of new diagnostic methods during pregnancy, diagnosis, identification, and treatment of patients with these disorders remain a serious problem in fetal and maternal medicine (Resnik, Lockwood, Moore, Greene, Copel, \& Silver, 2018). Prenatal diagnosis of heart abnormalities is vital step in managing this problem. In this regard, fetal echocardiography is suggested as a standard part of screening for the following reasons (Rychik, Ayres, Cuneo, Gotteiner, Hornberger, Spevak, \& Van Der Veld, 2004):

1- Decide to terminate or continue the pregnancy (termination of pregnancy in incurable and debilitating anomalies).

2- Identify and diagnose associated syndromes such as DJ, Down syndrome, sclerosis, tuberculosis, etc.

3- Starting intrauterine therapies such as treatment of fetal arrhythmias, pericardial fluid drainage, etc.

4- Early treatment of the disease in the first days of life (before causing complications) such as arterial switching in the movement of large arteries.

5- Diagnosis and management of maternal diseases such as diabetes and lupus.

6- Psychological support of the parents.

Today, one of the most important parts of prenatal screening is fetal echocardiography, which is used to diagnose fetal heart disorders. Assessing the incidence of cardiac abnormalities in IUGR fetuses can well illustrate the relationship between these two complications. However, to the best of our knowledge, no studies have evaluated echocardiographic findings in IUGR fetuses. In the present study, the incidence of cardiac abnormalities in fetuses affected by IUGR as well as factors related to the occurrence of these abnormalities were evaluated.

\section{Material and Methods}

\subsection{Study Design}

In this descriptive-analytical study, pregnant women referred to the Imam Khomeini Hospital in Ahvaz during February 2018 to January 2020 were recruited. Confirmed cases with diagnosis of IUGR or SGA were included. While those with chromosomal or structural disorders, premature rupture of membrane and chorioamnionitis were excluded. The study has reviewed and confirmed by Ahvaz Jundishapour University of Medical Sciences Ethics Committee. Signed inform consent were obtained from all participants.

\subsection{Measurements}

Complete clinical information was recorded using a questionnaire. The recorded information included age, birth weight, gestational age, weight and BMI and comorbidities. Then, echocardiographic data; structural abnormalities including septal condition, valves and outflow of large arteries, and the presence of mass or oxygen in the heart and pulmonary arteries, EF and HR, were extracted from the medical records.

\subsection{Statistical Analysis}

The data were presented by descriptive statistics including mean, median, standard deviation and frequency. The means were compared by independent t-test. The proportions were compared using Chi-Square tests. In order to determine the predictive factors of fetal heart failure, univariate and multivariate regression analyses were performed. All statistical analyses were carried out using SPSS version 20. The p value less than 0.05 considered significant.

\section{Results}

In the present study, 152 patients were studied. The mean age of patients was 28.2 ranged from 17- to 40year. The mean body mass index (BMI) was 28.4 with the range of 18 to 39.5 . The mean gestational age at the time of admission was 32.7 weeks (22.2 to 36.5 weeks). Pregnancy hypertension (GTHN) with a frequency of $17.1 \%$ and gestational diabetes with a frequency of $16.4 \%$ were the most common underlying diseases. Seventeen cases $(11.2 \%)$ were pregnant using assisted reproductive techniques. 
Table 1. Characteristics of the studied mothers

\begin{tabular}{ll}
\hline Characteristics & Mean(range) \pm SD or Frequency(\%) \\
\hline Age (y) & $28.2(17-40) \pm 6.7$ \\
BMI (kg/m $\left.{ }^{2}\right)$ & $28.4(18-39.5) \pm 4.8$ \\
Gestational Age(week) & $32.7(22.29-36.57) \pm 2.57$ \\
Comorbidities & \\
GTHN & $26(17.1 \%)$ \\
GDM & $25(16.4 \%)$ \\
Hypothyroidism & $8(5.3 \%)$ \\
Hyperthyroidism & $9(5.9 \%)$ \\
Normal & $84(55.3 \%)$ \\
Pregnancy & \\
Spontaneous & $135(88.8 \%)$ \\
ART cycles & $17(11.2 \%)$ \\
\hline
\end{tabular}

According to fetal ultrasound, it was found that Abdominal circumference (AC) levels were abnormal in 65.1\% of cases. Abnormal Estimation of Fetal Weight (EFW) was also observed in $38.1 \%$ of cases. On the other hand, during doppler ultrasound it was found that $55.9 \%$ had an abnormal umbilical artery Perfusion Index (PI), $11.8 \%$ had an abnormal central PI artery, and 34.2\% had an abnormal uterine artery PI. Finally, 50 fetuses (32.9\%) had SGA and another 102 were identified as IUGR.

Table 2. Ultrasound characteristics of the studied participants

\begin{tabular}{ll}
\hline Characteristics & Median(range) - Frequency(\%) \\
\hline Abdominal Circumference & \\
Normal & $53(34.8 \%)$ \\
Abnormal & $99(65.1 \%)$ \\
Estimated Fetal Weight & \\
Normal & $93(61.1 \%)$ \\
Abnormal & $59(38.81 \%)$ \\
Umbilical artery PI & $1.17(0.65-2.1)$ \\
Normal & $67(44.1 \%)$ \\
Abnormal & $85(55.9 \%)$ \\
Middle cerebral artery & $1.99(0.55-3.37)$ \\
Normal & $134(88.2 \%)$ \\
Abnormal & $18(11.8 \%)$ \\
Mean Uterine artery PI & $0.67(0.44-1.67)$ \\
Normal & $100(65.78 \%)$ \\
Abnormal & $52(34.2 \%)$ \\
IUGR/SGA & \\
IUGR Stage I & \\
IUGR Stage II & $79(52 \%)$ \\
IUGR Stage III & $14(9.2 \%)$ \\
IUGR Stage IV & $8(5.3 \%$ \\
SGA & $1(0.7 \%)$ \\
\hline
\end{tabular}


Table 3. Spectrum of fetal heart abnormalities

\begin{tabular}{lll}
\hline Characteristics & Frequency & Percent \\
\hline Normal & 63 & 41.4 \\
VSD & 21 & 13.8 \\
ASD & 15 & 9.9 \\
ASD \& VSD & 17 & 11.2 \\
Mild RVE & 4 & 2.6 \\
AS \& MS & 5 & 3.3 \\
TGA\&MR\&MS & 4 & 2.6 \\
Mild PS & 8 & 5.3 \\
Hydrops fetalis & 4 & 2.6 \\
Large PFO & 3 & 2.0 \\
Arrhythmia & 3 & 2.0 \\
LVE and LVH & 3 & 2.0 \\
TR and MR & 2 & 1.3 \\
\hline
\end{tabular}

Table 4. Comparison of fetus with and without abnormal echocardiographic feature

\begin{tabular}{|c|c|c|c|}
\hline \multirow{2}{*}{ Characteristics } & \multicolumn{2}{|c|}{ Echo Cardiography findings } & \multirow{2}{*}{ P value } \\
\hline & Normal & Abnormal & \\
\hline SGA/IUGR & & & 0.0001 \\
\hline$S G A$ & $28(56 \%)$ & $22(44 \%)$ & \\
\hline IUGR Stage I & $34(43 \%)$ & $45(57 \%)$ & \\
\hline IUGR Stage II & $0(0 \%)$ & $14(100 \%)$ & \\
\hline IUGR Stage III & $1(12.5 \%)$ & $7(87.5 \%)$ & \\
\hline IUGR Stage IV & $0(0 \%)$ & $1(100 \%)$ & \\
\hline IUGR type & & & 0.164 \\
\hline Early & $8(22.2 \%)$ & $28(77.8 \%)$ & \\
\hline Late & $20(37.7 \%)$ & $33(62.3 \%)$ & \\
\hline Mean PI Uterine & & & 0.001 \\
\hline Normal & $51(51 \%)$ & $49(49 \%)$ & \\
\hline Abnormal & $12(23.1 \%)$ & $40(76.9 \%)$ & \\
\hline PI umbilical & & & 0.008 \\
\hline Normal & $36(53.7 \%)$ & $31(46.3 \%)$ & \\
\hline Abnormal & $27(31.8 \%)$ & $58(68.2 \%)$ & \\
\hline PI MCA & & & 0.12 \\
\hline Normal & $59(44 \%)$ & $75(56 \%)$ & \\
\hline Abnormal & $4(22.2 \%)$ & $14(77.8 \%)$ & \\
\hline
\end{tabular}

Table 5. Univariate and multivariate regression model

\begin{tabular}{|c|c|c|c|c|}
\hline \multirow{2}{*}{ Variables } & \multicolumn{2}{|l|}{ Univariate } & \multicolumn{2}{|l|}{ Multivariate } \\
\hline & $\mathrm{OR}(95 \% \mathrm{CI})$ & P-Value & $\mathrm{OR}(95 \% \mathrm{CI})$ & P-Value \\
\hline Age & $1.0(0.96-1.05)$ & 0.74 & & \\
\hline BMI & $0.94(0.87-1)$ & 0.079 & $1.1(01.001-1.3)$ & 0.052 \\
\hline ART cycle & $1.8(0.6-5.4)$ & 0.29 & & \\
\hline $\mathrm{AC}$ & $0.74(0.38-1.4)$ & 0.36 & & \\
\hline EFW & $0.9(0.63-4.4)$ & 0.819 & & \\
\hline PI UMB & $2.49(1.28-4.8)$ & 0.007 & $3.39(1.4-8.2)$ & 0.007 \\
\hline Mean PI uterine & $3.46(1.6-7.3)$ & 0.001 & $6.04(2.07-17.5)$ & 0.001 \\
\hline Early IUGR & $2.17(1.02-4.6)$ & 0.042 & $2.17(0.94-5.04)$ & 0.069 \\
\hline
\end{tabular}

Fetal echocardiography showed that nearly $60 \%$ of fetuses had heart abnormalities. The most common disease was ventricular septal defect (VSD) $(n=21,13.8 \%)$, followed by atrial septal defec (ASD) $(n=15,9.9 \%)$ and concurrent ASD and VSD was observed in of $11.2 \%$ cases $(n=17)$ (Table 3$)$. Based on that, the patients were divided into two major groups; normal and abnormal fetal heart. It was found that the incidence of 
echocardiographic abnormalities in IUGR fetuses was significantly higher than in SGA $(p=0.0001)$. However, the type of IUGR did not have a significant relationship with the incidence of echocardiographic findings in terms of time of performance (Early or late). Among the Doppler ultrasound factors, uterine artery PI $(p=0.001)$ and umbilical artery PI $(\mathrm{p}=0.008)$ were associated with fetal heart abnormalities (Table 4$)$.

In order to determine the predictive factors of fetal heart failure, univariate and multivariate regression analyses were performed. Based on this, it was found that impaired uterine artery PI and umbilical artery PI independently predict fetal echocardiographic abnormalities (Table 5).

\section{Discussion}

The findings of the present study showed that the occurrence of cardiovascular disorders is associated with IUGR. Thus, its incidence was significantly higher in IUGR than in normal fetuses. In line with our results, previous studies have also shown association of IUGR with many cardiovascular disorders. Niewiadomska et al. showed that children with IUGR had subclinical myocardial disorders (Niewiadomska-Jarosik, Zamojska, Zamecznik, Stańczyk, Wosiak, \& Jarosik, 2017). Fouzas et al. Reported that IUGR infants showed changes in subclinical changes in cardiac morphological that may lead to altered adaptation pattern of cardiovascular system with extra uterine life (Fouzas, Karatza, Davlouros, Chrysis, Alexopoulos, Mantagos, \& Dimitriou, 2014). Another study of 209 IUGR or SGA, and 150 healthy fetuses as a control group showed that IUGR and SGA fetuses had larger and more spherical hearts compared to the control group. Impaired systolic and diastolic performance including decreased Tricuspid annular plane systolic excursion (TAPSE) and increased left ventricular performance index (LVGFI) was reported (Pérez - Cruz, Cruz - Lemini, Fernández, Parra, Bartrons, Gómez-Roig, Crispi, \& Gratacós, 2015). Sehgal et al. In their study of heart function and biochemical characteristics of arteries in SGA infants showed that the Ponderal index was significantly lower and the blood pressure was significantly higher in SGA infants than AGA. Ventricular output is lower in SGA infants and the diastolic function impairment is higher. Moreover, the isovolumic relaxation time is longer in the SGA infants (Sehgal, Doctor, \& Menahem, 2013). In the present study, unlike to the Segah et al's study, different types of IUGR and SGA were studied and compared separately.

Our findings also showed that uterine artery PI and umbilical artery PI could independently predict the incidence of heart disorders in IUGR/SGA fetuses. Graupner et al. Showed that congenital heart disease is associated with changes in Doppler patterns, especially with increased uterine artery PI (Graupner, Koch, Enzensberger, Götte, Wolter, Müller, Kawecki, Herrmann, \& Axt-Fliedner, 2019). Abnormal uterine artery Doppler suggests impaired placentation and poor placental function. In the present of uteroplacental insufficiency, increased placental resistance reduces end-diastolic flow in the umbilical artery. Then during pregnancy, the subsequent further increase in placental resistance, end-diastolic flow may be absent or even reverse. As a result of these changes, cardiac damage may occur, leading to an increase in central venous pressure, which manifests itself with an increase in PI or even reversibility of the flow of ductus or umbilical veins (Baschat \& Harman, 2001; Turan et al., 2008; Spinillo, Gardella, Bariselli, Alfei, Silini, \& Bello, 2014; Mari, Hanif, Kruger, Cosmi, Santolaya-Forgas, \& Treadwell, 2007; Brantberg \& Sonesson, 1999).

\section{Limitations of the Study}

Given the very few studies that have been done in this area, justifying the findings of this study requires further investigation.

\section{Conclusion}

In general, the findings of this study showed that the incidence of heart disorders in IUGR fetuses is high and is related to the severity of fetal growth restriction. Cardiac abnormalities are more common in IUGR fetuses than in SGA. Our results have also shown that the umbilical artery PI and uterine artery PI can be used as predictive factors in diagnosing fetal heart abnormalities. Our findings suggest an evaluation of echocardiography in IUGR fetuses.

\section{Conflict of interests}

The authors declare that there is no conflict of interests regarding the publication of this paper.

\section{References}

Baschat, A. A., \& Harman, C. R. (2001). Antenatal assessment of the growth restricted fetus. Curr Opin Obstet Gynecol, 13, 161-8. https://doi.org/10.1097/00001703-200104000-00011

Brantberg, A., \& Sonesson, S. E. (1999). Central arterial hemodynamics in small-for- gestational-age fetuses before and during maternal hyperoxygenation: A Doppler velocimetric study with particular attention to the 
aortic isthmus. Ultrasound Obstet Gynecol, 14, 237-43. https://doi.org/10.1046/j.1469-0705. 1999.14040237.x

Carvalho, J. S., Allan, L. D., Chaoui, R., Copel, J. A., ..., \& Yagel, S. (2013). ISUOG Practice Guidelines (updated): Sonographic screening examination of the fetal heart. Ultrasound in Obstetrics \& Gynecology, 41(3), 348-59. https://doi.org/10.1002/uog. 12403

Cohen, E., Wong, F. Y., Horne, R. S., \& Yiallourou, S. R. (2016). Intrauterine growth restriction: Impact on cardiovascular development and function throughout infancy. Pediatric Research, 79(6), 821-30. https://doi.org/10.1038/pr.2016.24

Drose, J. A. (2013). Fetal echocardiography. Amsterdam: Elsevier Health Sciences.

Fouzas, S., Karatza, A. A., Davlouros, P. A., Chrysis, D., Alexopoulos, D., Mantagos, S., \& Dimitriou, G. (2014). Neonatal cardiac dysfunction in intrauterine growth restriction. Pediatric Research, 75(5), 651. https://doi.org/10.1038/pr.2014.22

Graupner, O., Koch, J., Enzensberger, C., Götte, M., Wolter, A., Müller, V., Kawecki, A., Herrmann, J., \& Axt-Fliedner, R. (2019). Cerebroplacental and uterine doppler indices in pregnancies complicated by congenital heart disease of the fetus. Ultraschall in der Medizin-European Journal of Ultrasound. https://doi.org/10.1055/a-0900-4021

Krishna, U., \& Bhalerao, S. (2011). Placental insufficiency and fetal growth restriction. The Journal of Obstetrics and Gynecology of India, 61(5), 505-11. https://doi.org/10.1007/s13224-011-0092-x

Mari, G., Hanif, F., Kruger, M., Cosmi, E., Santolaya-Forgas, J., \& Treadwell, M. C. (2007). Middle cerebral artery peak systolic velocity: A new Doppler parameter in the assessment of growth-restricted fetuses. Ultrasound Obstet Gynecol, 29, 310-6. https://doi.org/10.1002/uog.3953

Niewiadomska-Jarosik, K., Zamojska, J., Zamecznik, A., Stańczyk, J., Wosiak, A., \& Jarosik, P. (2017). Myocardial dysfunction in children with intrauterine growth restriction: An echocardiographic study. Cardiovascular Journal of Africa, 28(1), 36. https://doi.org/10.5830/CVJA-2016-053

Pérez-Cruz, M., Cruz-Lemini, M., Fernández, M. T., Parra, J. A., Bartrons, J., Gómez-Roig, M. D., Crispi, F., \& Gratacós, E. (2015). Fetal cardiac function in late-onset intrauterine growth restriction vs small-forgestational age, as defined by estimated fetal weight, cerebroplacental ratio and uterine artery Doppler. Ultrasound in Obstetrics \& Gynecology, 46(4), 465-471. https://doi.org/10.1002/uog.14930

Resnik, R., Lockwood, C. J., Moore, T., Greene, M. F., Copel, J., \& Silver, R. M. (2018). Creasy and Resnik's Maternal-Fetal Medicine: Principles and Practice E-Book. Elsevier Health Sciences.

Rychik, J., Ayres, N., Cuneo, B., Gotteiner, N., Hornberger, L., Spevak, P. J., \& Van Der Veld, M. (2004). American Society of Echocardiography guidelines and standards for performance of the fetal echocardiogram. Journal of the American Society of Echocardiography, 17(7), 803-10. https://doi.org/10.1016/j.echo.2004.04.011

Satomi, G. (2015). Guidelines for fetal echocardiography. Pediatr Int, 57, 1-21. https://doi.org/10.1111/ped.12467

Sehgal, A., Doctor, T., \& Menahem, S. (2013). Cardiac function and arterial biophysical properties in small for gestational age infants: Postnatal manifestations of fetal programming. The Journal of Pediatrics, 163(5), 1296-300. https://doi.org/10.1016/j.jpeds.2013.06.030

Sharma, D., Shastri, S., \& Sharma, P. (2016). Intrauterine growth restriction: Antenatal and postnatal aspects. Clinical Medicine Insights: Pediatrics. https://doi.org/10.4137/CMPed.S40070

Spinillo, A., Gardella, B., Bariselli, S., Alfei, A., Silini, E. M., \& Bello, B. D. (2014). Cerebropla- cental Doppler ratio and placental histopathological features in pregnan- cies complicated by fetal growth restriction. $J$ Perinat Med, 42, 321-8. https://doi.org/10.1515/jpm-2013-0128

Turan et al. (2008). Progression of Doppler abnor- malities in intrauterine growth restriction. Ultrasound Obstet Gynecol, 32, 160-7. https://doi.org/10.1002/uog.5386

\section{Copyrights}

Copyright for this article is retained by the author(s), with first publication rights granted to the journal.

This is an open-access article distributed under the terms and conditions of the Creative Commons Attribution license (http://creativecommons.org/licenses/by/4.0/). 